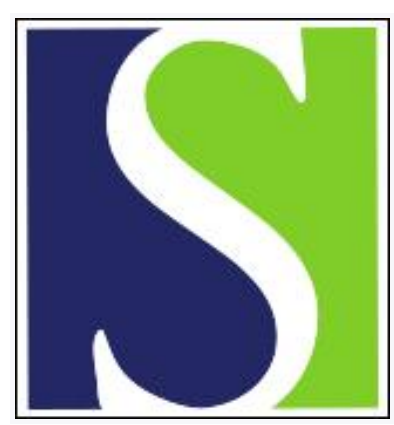

Scand J Work Environ Health 1998;24(5):334-343

https://doi.org/10.5271/sjweh.353

Issue date: Oct 1998

Job strain and ambulatory blood pressure among female white-collar workers

by Laflamme N, Brisson C, Moisan J, Milot A, Mâsse B, Vézina M

The following articles refer to this text: $2003 ; 29(3): 206-215$;

2004;30(2):85-128; 2004;30(6):477-485; 2007;33(4):304-317;

2014;40(2):109-132

Key terms: blood pressure; cardiovascular risk factor; education; occupational stress; psychological stress

This article in PubMed: www.ncbi.nlm.nih.gov/pubmed/9869304 


\title{
Job strain and ambulatory blood pressure among female white-collar workers
}

\author{
by Nathalie Laflamme, PhD, ${ }^{1,2}$ Chantal Brisson, PhD, ${ }^{1,2}$ Jocelyne Moisan, PhD, ${ }^{2,3}$ Alain Milot, MD, 1,3,4 \\ Benoit Mâsse, PhD, ${ }^{1}$ Michel Vézina, $M D^{2}$
}

\begin{abstract}
Laflamme N, Brisson C, Moisan J, Milot A, Mâsse B, Vézina M. Job strain and ambulatory blood pressure among female white-collar workers. Scand J Work Environ Health 1998;24(5):334-343.

Objectives The association between job strain and ambulatory blood pressure was studied among female whitecollar workers.

Methods This cross-sectional investigation studied 210 women in high- or low-strain jobs randomly selected from 3183 women of all ages, employed as white-collar workers. The women wore an ambulatory blood pressure monitor for 24 hours during a workday. Mean blood pressures were calculated. Psychological demands and decisional latitude were measured twice (14 months before and 7 days before the blood pressure measurement) with 2 scales recommended by Karasek.

Results Significant differences in blood pressure were found according to current job strain among the women holding a university degree. Their mean blood pressures during work were significantly higher $[8.0 \mathrm{~mm} \mathrm{Hg}(1.1$ $\mathrm{kPa})$ systolic and $6.4 \mathrm{~mm} \mathrm{Hg}(0.8 \mathrm{kPa})$ diastolic blood pressure] in the high-strain group than in the low-strain group. Statistically significant elevations in blood pressure over the 24-hour period were also found for women with a university degree. Cumulative exposure to high strain over 14 months was also significantly associated with high systolic blood pressure at work, in the evening, and over a 24-hour period irrespective of other factors related to blood pressure. Among the women without a university degree, the blood pressure differences observed between the job strain groups were less than $1 \mathrm{~mm} \mathrm{Hg}(0.1 \mathrm{kPa})$ and not statistically significant.

Conclusions These results provide support for the effect of job strain on ambulatory blood pressure only among female white-collar workers holding a university degree.
\end{abstract}

Key terms blood pressure, cardiovascular risk factor, education, occupational stress, psychological stress.

Since 1980, several studies have been conducted on the association between occupational stress and cardiovascular diseases $(1,2)$. Research based on the job-strain model developed by Karasek (3) has led to the largest group of studies using a common conceptual model. This model postulates that high psychological demands (defined by the quantity and the complexity of work, and time constraints) combined with low decisional latitude (defined by the individual's control over one's work and the use of one's qualifications) produce high job strain. It is hypothesized that this high job strain increases the risk of developing physical or psychological health problems (4). Several studies have found some evidence of an association between job strain (or 1 of its components) and cardiovascular diseases (2). The relationship between job strain and elevation in blood pressure, one of the most important cardiovascular risk factors, has also been studied (5-23). A significant positive association between job strain and blood pressure was reported in 10 of 19 studies $(8,10-15,18,20,22)$. Inconsistency in the results could be explained, at least partly, by the use of different methodologies. Most of the studies were cross-sectional $(5-12,14,15,17,21-23)$. Three studies used a job-strain measure assessed by giving each

Laval University Epidemiology Research Group, Quebec, Canada.

Interdisciplinary Research Group on Organization, Health and Safety at Work, Quebec, Canada.

Pharmaco-epidemiology Research Team, Laval University, Quebec, Canada.

Department of Medicine, Laval University, Quebec, Canada.

Reprint requests to: Dr Nathalie Laflamme, Laval University Epidemiology Research Group, Centre hospitalier affilié universitaire de Québec, Pavillon Saint-Sacrement, 1050, chemin Sainte-Foy, Québec (Québec), Canada, G1S 4L8. [E-mail: NLaflamme@cspq.qc.ca] 
subject a score corresponding to the mean score for their occupation $(21-23)$. Several studies relied on casual blood pressure measures usually taken outside the work environment $(5,7,9,10,15,17,19,21)$. Other studies used ambulatory blood pressure measures usually taken at work and sometimes throughout the day with an ambulatory monitor worn by each subject $(6,8,11-14,16$, $18,20,22,23)$. Eight of 11 studies that used an ambulatory monitor found a significant association with job strain $(8,11-14,18,20,22)$.

Assessing the effect of job strain on blood pressure in women is particularly relevant. Indeed, an increasing proportion of women are professionally active in most industrialized countries (24). In addition, the proportion of women exposed to psychosocial constraints at work has been found to be higher than for men $(7,15,17,25$, 26). Despite this fact, studies evaluating the effect of job strain on blood pressure have been conducted twice as often among men $(5-11,13-23)$ as among women (7, $8,11,12,14,15,17-19)$. However, evidence of a possible association between job strain and blood pressure was found in the same proportions in studies conducted among women, 4 of 9 studies $(8,12,14,15)$, as in studies conducted among men, 7 of 18 studies $(8,10,11,13$, $18,20,22$ ).

The objective of our study was to measure the relationship between job strain and ambulatory blood pressure among white-collar women. The specific objective was to determine whether high job strain (current exposure and cumulative exposure over 14 months) was associated with an elevation in systolic and diastolic blood pressure at work. This hypothesis was also tested in relation to blood pressure measured in the evening, at night, and over a 24-hour period.

\section{Subjects and methods}

\section{Study design and selection of the study population}

A cross-sectional study was conducted in Quebec City (Canada). The study population was selected in 2 steps (figure 1). There was an initial selection in 1991-1993 and then a 2nd selection in 1993-1994.

Initial selection (1991-1993). The subjects were identified with the use of data from a previous investigation on the work environment and cardiovascular diseases (Medical Research Council of Canada \#90090P-19499. CBA-35698). All the women employed as white-collar workers in 8 organizations were invited to participate in this previous investigation between January 1991 and March 1993. This population was recruited in the context of a large cardiovascular health promotion program for working men and women of all ages. The total number of workers in each organization varied from 282 to 3249 for a total of 9169 . The overall participation among the women was $76 \%$. Fifty percent of the study population came from 3 large organizations recruited by the researchers based on an a priori impression of possibly high job strain (jobs involving repetitive tasks, a semipublic insurance company, and an income taxation service). Other organizations were chosen from public agencies and recruited by the team of the cardiovascular health promotion program. For this 1 st investigation, the subjects completed a questionnaire about their history of cardiovascular diseases, cardiovascular risk factors, lifestyle, job characteristics, and sociodemographic variables. Height, weight, and blood pressure were also measured. Due to the high cost and large amount of time needed to monitor blood pressure, we limited the number of women to the minimum needed for sufficient statistical power. We therefore took advantage of our data base to select women exposed to high or low levels of job strain. Other selection criteria were also applied to maximize the power by restricting the number of factors to be controlled in the analysis. The eligibility criteria for the present study were age between 18 and 64 years, work lasting $\geq 35$ hours a week in a job involving high strain (high psychological demands and low decisional latitude) or low strain (low psychological demands and high decisional latitude). The exclusion criteria were a body mass index of $\geq 27 \mathrm{~kg} / \mathrm{m}^{2},>2$ drinks of alcohol per day, antihypertensive medication, diabetes, or a history of coronary, cerebrovascular or peripheral vascular disease confirmed by a physician. Given that a complementary objective of the study was to evaluate the effect of family responsibilities on blood pressure (Brisson $\mathrm{C}$ et al, unpublished manuscript), women with children in shared custody were also excluded. A total of 689 women met our criteria. Eligible women were then stratified into 2 groups according to their work characteristics (high or low strain), and a random sample of about 200 women was drawn from each of the 2 groups to reach the final optimal sample size of 100 per group after the 2 nd selection.

Second selection (1993-1994). The women previously selected were contacted by telephone between October 1993 and May 1994. Women were included if they were still eligible according to the initial criteria. Moreover, those meeting the following criteria were excluded: worked for $>10$ hours a week in another job, no longer worked in the same organization, worked in a far away building, were on sick leave, were pregnant, breast-feeding or on maternity leave, looked after a physically or intellectually handicapped child or adult (particular stress), or had definite angina pectoris classified by the Rose questionnaire (27) (to minimize any possible influence of medication on blood pressure). 


\section{Data collection}

Data were collected from 2 sources. Eligibility criteria for the initial selection (including job strain at time 1) and information on personality were taken from the 1991 - 1993 data base. All other data were collected between October 1993 and June 1994. The women selected were contacted by telephone and met at the worksite. They had to complete a self-administered questionnaire on work and family characteristics, life-style, and sociodemographic variables. Weight and height were measured. In the 2 weeks following the questionnaire, ambulatory blood pressure was recorded using the Spacelabs 90207 monitor (Spacelabs Produits Médicaux Ltée, St Laurent, Québec, Canada). The subjects wore the monitor for 24 hours during a usual workday. The measures were taken every 15 minutes between 0700 and 2200 and every 30 minutes between 2200 and 0700 . Monday and Friday were excluded to eliminate possible variations due to the proximity of the weekend. Each woman also completed a diary indicating her posture, physical activity, and the occurrence of any stressful event for each blood pressure reading.

\section{Blood pressure}

Average systolic and diastolic blood pressures were calculated for each of the following periods: at work (0900 - 1600, morning: $0900-1230$; afternoon: $1230-$ $1600)$, in the evening $(1700-2100)$, and at night $(2400$ - 0600). The end-of-evening period was brought forward to 2100 because of incomplete information about the sleeping period, therefore ensuring that women would be awake during the period of interest. In addition, 24hour blood pressure averages were calculated using mean hourly blood pressures. The subjects with missing data for at least 1 hourly blood pressure average were given a missing value for the 24-hour mean.

\section{Job strain}

Job strain was assessed at 2 different times, namely, for the initial investigation in 1991-1993 (job strain at time 1) and for this study (the 2nd selection) in 1993-1994 (current job-strain exposure or job strain at time 2). Psychological demands and decisional latitude were assessed with the two 9-item scales of Karasek's job content questionnaire (28). The validity of a preliminary version of these 2 scales has been studied earlier (4). For this preliminary version, evidence has been reported regarding internal reliability (29), test-retest reliability within occupational codes (4), and construct validity $(3,4)$. The internal reliability of the two 9 -item scales has also been documented (30). The internal consistency $(0.73$ for psychological demands and 0.83 for decisional latitude), factorial validity, and discriminant validity have been documented for the French version used by us (31). In our study, the scores for psychological demands and decisional latitude were dichotomized at the median of the distribution of a random sample of all workers in the province of Quebec (high psychological demands: score $\geq 24$ and low decision latitude: score $\leq 72)(15,32)$, as for the French validation study (31). Job strain at time 1 was categorized as follows: workers exposed to both high psychological demands and low decisional latitude composed the high-strain group, and workers not exposed to either job constraint composed the low-strain group. None of the women were exposed to only 1 of these constraints at time 1 since this was a selection criterion. Current job-strain exposure (job strain at time 2) was categorized in the same way, but 2 intermediate exposure groups were also defined. These 2 groups included the subjects exposed only to low latitude, that is, the passive group, and subjects exposed only to high demands, the active group. Since job strain was measured at 2 different times, cumulative exposure to job strain was assessed. The 4 groups were women exposed to high strain at times 1 and 2, women exposed to high strain only at time 1 , women exposed to high strain only at time 2 , women not exposed to high job strain at either times.

\section{Other relevant variables}

Body mass index was defined by weight in kilograms divided by height in meters squared. Smokers were defined as subjects smoking at least 1 cigarette a day. Alcohol use was measured by the average number of drinks of alcohol consumed per week in the last 12 months (a drink being a glass of beer, a glass of wine, or an ounce of hard liquor). Physical activity during leisure time was measured by the number of times per week the subject engaged in a vigorous physical activity lasting at least 20 minutes. Oral contraceptive use was defined according to current use. The demographic and work-related variables measured by the questionnaire included age, degree of education completed, occupation, number of hours worked per week, and family income. Physical effort at work was defined with a question used in the Quebec Health Study of 1987 (33). Social support at work was measured by an 8-item scale of the job content questionnaire (28). The measure of social support outside work was composed of answers to 4 questions on available social support (advising or listening) that were used in the Quebec cardiovascular study (32). Personality was evaluated with a variable composed of 5 questions on hostility taken from the Cook-Medley hostility scale (34) and 3 questions on anger taken from the Haynes et al study (35). In addition, difficulty to express feelings was measured using 5 questions adapted from the alexithymia construct validated by Taylor et al (36).

\section{Analysis}

The crude mean blood pressures at work were calculated for each category of factors influencing blood 
pressure. Statistical comparisons of mean blood pressures within the factor's categories were done using the F statistic obtained from an analysis of variance with a significance level of 0.05 . Linear trends were tested using ordinal variables in a linear regression.

The crude mean blood pressure for each job strain category and the differences of the mean blood pressures between each exposed group and the unexposed group were then calculated.

All the analyses concerning job strain and blood pressure were done separately for each systolic and diastolic blood pressure, for each time period (work, evening, night, and 24 hours), and for each job-strain exposure (current and cumulative). The potentially modifying effect of age ( $25-39$ versus 40-64 years), education (with versus without university degree), size of organization (divided into 3 groups according to the number of workers in the organization), number of hours worked (3540 versus $>40$ hours), seniority at this job ( $<1$ year and $\geq 1$ year), and social support at work (divided at the median) were first evaluated in a stratified analysis. We then evaluated the statistical significance of the interaction using the F statistic obtained from an analysis of variance.

Potential confounders were evaluated using an analysis of covariance. Covariates were added one by one to the model containing only the job-strain exposure. To be included in the model, a covariate had to change at least 1 job strain coefficient by more than $10 \%$. The subsequent covariate was added to the model, which included the previous successful additions.

The adjusted mean blood pressures for each job-strain category and the differences of the adjusted mean blood pressures between each exposed group and the unexposed group were calculated using an analysis of covariance.

Student's $t$ test was used to determine whether the observed blood pressure differences between each exposed group and the unexposed group were statistically significant. Given that multiple comparisons were made, the Bonferroni correction was applied to maintain an overall significance level of 0.05 (37). Therefore, for the difference between an exposed category and the reference category to be considered significant, the critical threshold was $0.05 / 3=0.017$.

Psychological demands and decisional latitude, taken as continuous variables with an interaction term for "demand $x$ latitude", were also analyzed using linear regression. In addition, a composite score of current jobstrain exposure defined by psychological demands minus decision latitude (previously transformed to be on the same scale) (13) was also analyzed using linear regression. This score of current job-strain exposure, which does not imply a multiplicative effect of demand and latitude, has been found to be positively correlated with blood pressure (13).

\section{Results}

The selection of the study population is shown in figure 1. The reasons for exclusions during the initial selection process were a body mass index of $\geq 27(N=163)$, children in shared custody $(\mathrm{N}=79)$, antihypertensive medication ( $\mathrm{N}=26)$, diabetes $(\mathrm{N}=22)$, and $>2$ drinks of alcohol per day $(\mathrm{N}=4)$. During the second selection process, the largest number of exclusions involved 76 women who no longer worked in the same organization, 23 women who were working in a remote building, and 20 women who were pregnant, breast-feeding or on maternity leave. This exclusion process left us with 210 women for study. These women were either managers $(\mathrm{N}=4)$, professionals $(\mathrm{N}=64)$, technicians ( $\mathrm{N}=62)$, clerical employees $(\mathrm{N}=77)$, or other public service employees $(\mathrm{N}=3)$.

Among our 210 participants, the mean systolic and diastolic blood pressures at work were 119.6 (SD 8.2) and 76.9 (SD 6.3) $\mathrm{mm} \mathrm{Hg} \mathrm{[15.9} \mathrm{(SD} \mathrm{1.1)} \mathrm{and} \mathrm{10.2} \mathrm{(SD}$ $0.8 \mathrm{kPa})]$ respectively. The systolic and diastolic blood pressures were similar in the evening (118.9 (SD 8.4) and 76.0 (SD 6.5) $\mathrm{mm} \mathrm{Hg}$ [15.8 (SD 1.1) and 10.1 (SD 0.8) $\mathrm{kPa}$, respectively] and were lower at night, 99.6 (SD 6.8) and 59.0 (SD 5.7) [13.2 (SD 0.9) and $7.8($ SD 0.8) kPa, respectively]. Table 1 presents the mean blood pressures at work according to the main factors previously

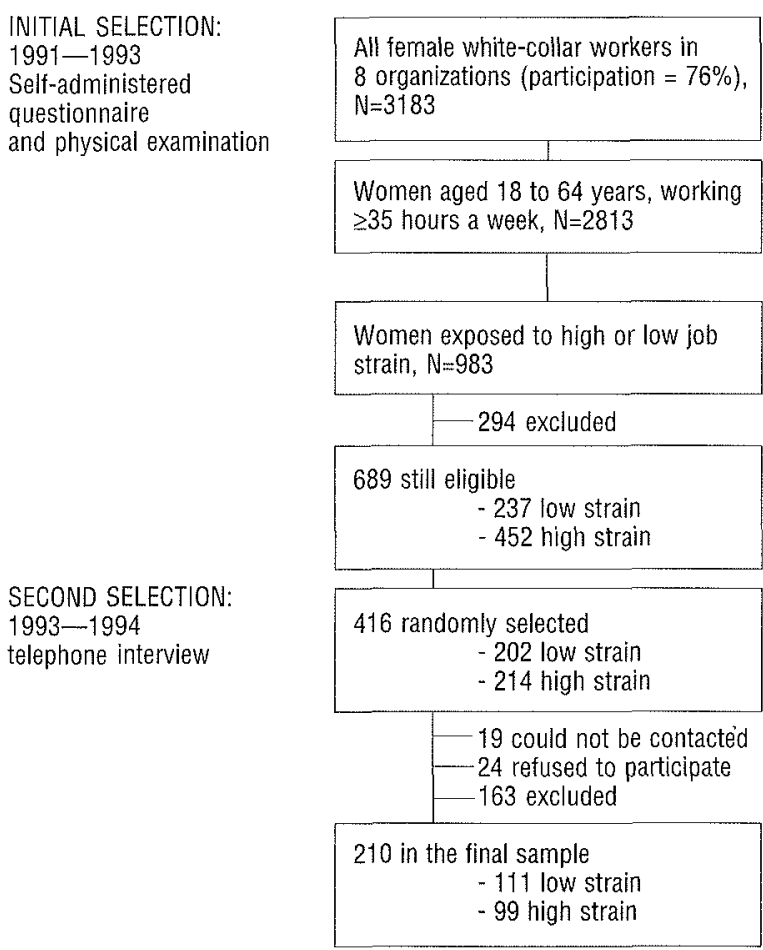

Figure 1. Selection of the study population. High strain was defined as high psychological demands and low decisional latitude; low strain was defined as low psychological demands and high decisional latitude. The intermediate exposure categories of high demands combined with high latitude and low demands combined with low latitude were excluded in the initial selection. 
Table 1. Systolic (SBP) and diastolic (DBP) blood pressures at work according to factors which can influence blood pressure, Quebec 1993-1994

\begin{tabular}{|c|c|c|c|c|c|}
\hline \multirow[t]{2}{*}{ Variables } & \multirow{2}{*}{$\begin{array}{l}\text { Number of } \\
\text { subjectsa }\end{array}$} & \multicolumn{2}{|c|}{$\mathrm{SBP}(\mathrm{mm} \mathrm{Hg})$} & \multicolumn{2}{|c|}{$\mathrm{DBP}(\mathrm{mm} \mathrm{Hg}$} \\
\hline & & Mean & $\mathrm{SD}$ & Mean & $\mathrm{SD}$ \\
\hline \multicolumn{6}{|l|}{ Age (years) } \\
\hline $25-34$ & 39 & 119.5 & 7.9 & 76.9 & 6.5 \\
\hline $35-44$ & 123 & 119.4 & 8.1 & 76.8 & 6.2 \\
\hline $45-54$ & 41 & 119.2 & 8.2 & 77.0 & 6.6 \\
\hline $55-64$ & 7 & 124.5 & 10.8 & 76.3 & 8.0 \\
\hline \multicolumn{6}{|l|}{$\begin{array}{l}\text { Education (last degree } \\
\text { completed) }\end{array}$} \\
\hline High school or less & 74 & 121.3 & 8.8 & 78.4 & 6.7 \\
\hline College or equivalent ${ }^{b}$ & 65 & 119.3 & 7.3 & 76.7 & 6.4 \\
\hline University & 71 & 118.0 & $8.0^{*}$ & 75.5 & $5.5^{\star}$ \\
\hline \multicolumn{6}{|l|}{ Body mass index $\left(\mathrm{kg} / \mathrm{m}^{2}\right)$} \\
\hline Low $(<21.45)$ & 69 & 119.1 & 8.1 & 77.4 & 6.5 \\
\hline Intermediate $(21.45-23.29)$ & 9) 67 & 119.0 & 7.8 & 76.7 & 5.8 \\
\hline High $(23.3-27.0)$ & 73 & 120.4 & 8.7 & 76.4 & 6.7 \\
\hline \multicolumn{6}{|l|}{ Smoking } \\
\hline No & 176 & 118.9 & 8.1 & 76.5 & 6.3 \\
\hline Yes & 34 & 122.9 & $8.1^{*}$ & 78.7 & 6.4 \\
\hline \multicolumn{6}{|l|}{ Alcohol use } \\
\hline$<1$ drink per week & 76 & 119.9 & 8.4 & 76.8 & 6.6 \\
\hline 1 to 5 drinks per week & 104 & 119.2 & 8.1 & 76.6 & 6.0 \\
\hline 6 to 14 drinks per week & 28 & 119.6 & 7.4 & 77.9 & 6.4 \\
\hline \multicolumn{6}{|l|}{ Leisure-time physical activity } \\
\hline$<1$ time per week & 84 & 120.6 & 9.6 & 77.3 & 7.5 \\
\hline 1 time per week & 38 & 118.0 & 7.7 & 76.6 & 5.3 \\
\hline 2 times per week & 52 & 119.6 & 6.5 & 76.5 & 5.3 \\
\hline$\geq 3$ times per week & 36 & 118.8 & 7.1 & 76.7 & 5.9 \\
\hline \multicolumn{6}{|l|}{ Use of oral contraceptives } \\
\hline No & 182 & 119.1 & 8.2 & 76.7 & 6.3 \\
\hline Yes & 27 & 122.8 & $7.5^{*}$ & 78.2 & 6.7 \\
\hline
\end{tabular}

a The totals of each variable may differ from 210 because of missing data.

In the province of Québec, college refers to preuniversity or technical studies.

* Significant association $(\mathrm{P}<0.05)$ between the variable and blood pressure using the $F$ statistic obtained from the analysis of variance. reported in the literature as being associated with blood pressure. Systolic blood pressure was significantly higher among the less-educated women (test of trend, $\mathrm{P}=0.01$ ), smokers, and women taking oral contraceptives. The same trend was observed for diastolic blood pressure, but these results were only statistically significant for education (test of trend, $\mathrm{P}=0.006$ ). Systolic blood pressure was higher among the older women $(\mathrm{N}=7)$, but the difference did not reach statistical significance. Body mass index, alcohol use, and leisure-time physical activity were not associated with blood pressure. All but 3 subjects reported low physical effort at work.

In our sample, $25 \%$ of the women were exposed to high strain at time 2 and thus were defined as currently exposed to high strain. Women with high strain had a slight elevation in blood pressure [systolic $2.0 \mathrm{~mm} \mathrm{Hg}$ $(0.3 \mathrm{kPa})$, diastolic $1.7 \mathrm{~mm} \mathrm{Hg}(0.2 \mathrm{kPa})]$ at work and in the evening when compared with women with low strain. These differences were not statistically significant. Other analyses revealed that the relationship between current job strain and blood pressure did not differ according to age, size of organization, number of hours worked, or social support at work. Interestingly, the association between current job-strain exposure and blood pressure (systolic or diastolic) was modified by educational level. The final statistical models used included the following covariates: age, education, smoking, and oral contraceptive use. The other investigated variables had no confounding effect. The results observed for systolic blood pressure are presented in table 2 . The relations observed with diastolic blood pressure (not shown) were similar. Among the women holding a university degree, those exposed to high job strain had an elevated systolic blood pressure of $8.0 \mathrm{~mm} \mathrm{Hg}(1.1 \mathrm{kPa})$ at work when

Table 2. Mean systolic blood pressures (SBP) and the differences between the means according to current job strain by education level, Quebec 1993-1994. (SE = standard error)

\begin{tabular}{|c|c|c|c|c|c|c|c|c|}
\hline \multirow[t]{3}{*}{ Period } & \multicolumn{4}{|c|}{ Subjects with university degree } & \multicolumn{4}{|c|}{ Subjects without university degree } \\
\hline & \multirow[t]{2}{*}{$N^{a}$} & \multicolumn{2}{|c|}{$\mathrm{SBP}(\mathrm{mm} \mathrm{Hg})$} & \multirow[t]{2}{*}{ P-valuec } & \multirow[t]{2}{*}{$\mathrm{N}^{\mathrm{a}}$} & \multicolumn{2}{|c|}{$\mathrm{SBP}\left(\mathrm{mm} \mathrm{H} \mathrm{g}^{\mathrm{b}}\right)$} & \multirow[t]{2}{*}{ P-value } \\
\hline & & $\begin{array}{l}\text { Meand or } \\
\text { difference }^{\mathrm{e}}\end{array}$ & SE & & & $\begin{array}{l}\text { Meand or } \\
\text { difference }\end{array}$ & $\mathrm{SE}$ & \\
\hline \multicolumn{9}{|c|}{ Work $(0900-1600)$} \\
\hline $\begin{array}{l}\text { Low strain } \\
\text { Passive } \\
\text { Active } \\
\text { High strain }\end{array}$ & $\begin{array}{l}17 \\
19 \\
21 \\
14\end{array}$ & $\begin{array}{l}113.3 \\
+3.3 \\
+3.7 \\
+8.0\end{array}$ & $\begin{array}{l}1.9 \\
2.6 \\
2.6 \\
2.8\end{array}$ & $\begin{array}{r}0.21 \\
0.15 \\
0.005\end{array}$ & $\begin{array}{l}29 \\
39 \\
32 \\
39\end{array}$ & $\begin{array}{l}119.2 \\
-0.8 \\
+0.1 \\
-0.7\end{array}$ & $\begin{array}{l}1.6 \\
2.0 \\
2.1 \\
2.0\end{array}$ & $\begin{array}{l}0.68 \\
0.95 \\
0.72\end{array}$ \\
\hline \multicolumn{9}{|c|}{ Evening $(1700-2100)$} \\
\hline $\begin{array}{l}\text { Low strain } \\
\text { Passive } \\
\text { Active } \\
\text { High strain }\end{array}$ & $\begin{array}{l}17 \\
19 \\
21 \\
13\end{array}$ & $\begin{array}{r}115.0 \\
+0.2 \\
+2.0 \\
+7.0\end{array}$ & $\begin{array}{l}2.0 \\
2.7 \\
2.7 \\
3.0\end{array}$ & $\begin{array}{l}0.93 \\
0.45 \\
0.02\end{array}$ & $\begin{array}{l}29 \\
39 \\
32 \\
39\end{array}$ & $\begin{array}{r}117.5 \\
-0.2 \\
+0.7 \\
-0.1\end{array}$ & $\begin{array}{l}1.6 \\
2.0 \\
2.1 \\
2.0\end{array}$ & $\begin{array}{l}0.9 \ddot{2} \\
0.75 \\
0.98\end{array}$ \\
\hline
\end{tabular}


compared with the women with low job strain $(\mathrm{P}=0.005)$. An elevation in blood pressure was also observed, but it was less important and not statistically significant for the women in the passive (low latitude) or active (high demand) groups. The multiplicative interaction between demands and latitude was tested (F statistic) and was not statistically significant $(P>0.15)$. In the evening, the elevation in systolic blood pressure associated with high strain was near the significance level. No significant effect of job strain on blood pressure was observed at night. For diastolic blood pressure at work (not shown), the level observed in the high-strain group was $6.4 \mathrm{~mm} \mathrm{Hg}(0.8$ $\mathrm{kPa})$ higher than that of the low-strain group $(\mathrm{P}=0.01)$. Among the women without a university degree, the differences in diastolic blood pressure observed between the current job strain categories were less than $1 \mathrm{~mm} \mathrm{Hg}(0.3$ $\mathrm{kPa}$ ). Figure 2 shows the hourly mean systolic blood pressures by current job strain among the women with a university degree. Among these women, the difference in systolic blood pressure between the high-strain group and the low-strain group was more pronounced during the work period, particularly in the afternoon. The elevation observed in the high-strain group averaged $5.5 \mathrm{~mm} \mathrm{Hg}$ $(0.7 \mathrm{kPa})(\mathrm{P}<0.05)$ in the morning and reached $10.5 \mathrm{~mm}$ $\mathrm{Hg}(1.4 \mathrm{kPa})(\mathrm{P}<0.001)$ in the afternoon. Over the $24-$ hour period the average elevation was $6.0 \mathrm{~mm} \mathrm{Hg}(0.8$ $\mathrm{kPa})$ and was also statistically significant $(\mathrm{P}=0.012)$. For the diastolic blood pressure (not shown), the average elevation over the 24-hour period was $4.8 \mathrm{~mm} \mathrm{Hg}(0.6 \mathrm{kPa})$ $(\mathrm{P}=0.017$ ). (A graph using medians instead of means yielded similar results.) The composite score of current job-strain, measured on a continuous scale (psychological demands minus decisional latitude), was analyzed. It yielded similar conclusions in that associations were found only for the women holding a university degree (not shown). Psychological demands and decisional latitude, taken as continuous variables, were not linearly associated with blood pressure, and there was also no interaction between these 2 factors.

Job strain exposure was assessed at 2 different times. The time intervals between the 2 measures ranged from 9.4 to 37.5 months with a median of 14.4 months. Due to recent rationalization in the participating organizations, there were substantial changes in the job-strain exposure between the 2 assessments. The proportion of the 210 women exposed to high strain at time 1 was $47 \%$, while only $25 \%$ were exposed to high strain at time 2 (current exposure). In all, 20\% of the women were exposed to high strain at both time 1 and time 2, thus defined as being exposed to cumulative high-strain exposure. The results concerning cumulative job strain and systolic blood pressure are presented in table 3 . Among

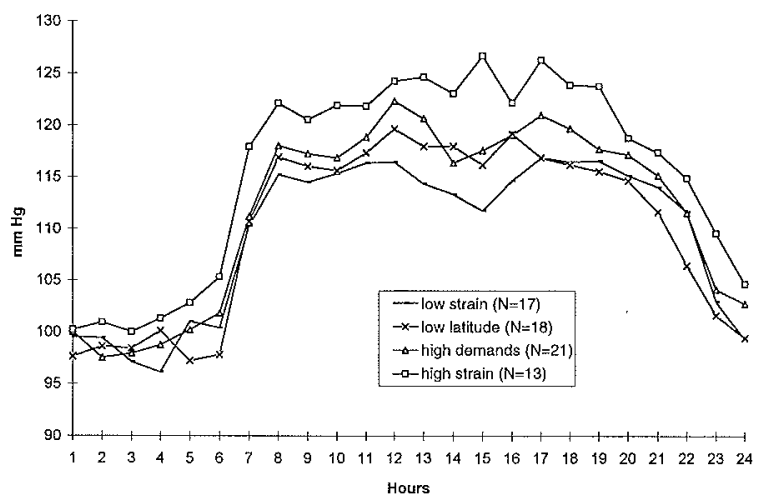

Figure 2. Hourly mean systolic blood pressure by current job strain exposure among women with a university degree, Quebec, 19931994. $(\mathrm{mm} \mathrm{Hg}=0.133 \mathrm{kPa})$

Table 3. Mean systolic blood pressures (SBP) and the differences between the means according to cumulative exposure to job strain by education level, Quebec 1991-1994. (T1=1991-1993, T2=1993-1994, SE = standard error)

\begin{tabular}{|c|c|c|c|c|c|c|c|c|}
\hline \multirow[t]{3}{*}{ Subjects } & \multicolumn{4}{|c|}{ Subjects with university degree } & \multicolumn{4}{|c|}{ Subjects without university degree } \\
\hline & \multirow[t]{2}{*}{$\mathrm{N}^{\mathrm{a}}$} & \multicolumn{2}{|c|}{$\mathrm{SBP}(\mathrm{mm} \mathrm{Hg})$} & \multirow[t]{2}{*}{ P-value c } & \multirow[t]{2}{*}{$\mathrm{Na}^{\mathrm{a}}$} & \multicolumn{2}{|c|}{$\mathrm{SBP}(\mathrm{mm} \mathrm{Hg})$} & \multirow[t]{2}{*}{$P$-value ${ }^{c}$} \\
\hline & & $\begin{array}{l}\text { Meand or } \\
\text { difference }^{\mathrm{e}}\end{array}$ & SE & & & $\begin{array}{l}\text { Meand or } \\
\text { difference }^{e}\end{array}$ & SE & \\
\hline \multicolumn{9}{|l|}{ Work $(0900-1600)$} \\
\hline $\begin{array}{l}\text { Unexposed at } \mathrm{T} 1 \text { and } \mathrm{T} 2 \\
\text { Exposed only at } \mathrm{T} 1 \\
\text { Exposed only at } \mathrm{T} 2 \\
\text { Exposed at } \mathrm{T} 1 \text { and } \mathrm{T} 2\end{array}$ & $\begin{array}{r}37 \\
20 \\
4 \\
10\end{array}$ & $\begin{array}{r}114.7 \\
+2.8 \\
+2.4 \\
+8.2\end{array}$ & $\begin{array}{l}1.3 \\
2.2 \\
4.2 \\
2.8\end{array}$ & $\begin{array}{r}0.20 \\
0.56 \\
0.004\end{array}$ & $\begin{array}{r}64 \\
36 \\
6 \\
33\end{array}$ & $\begin{array}{r}119.2 \\
-0.9 \\
-1.5 \\
-0.6\end{array}$ & $\begin{array}{l}1.1 \\
1.7 \\
3.4 \\
1.7\end{array}$ & $\begin{array}{l}0.59 \\
0.65 \\
0.72\end{array}$ \\
\hline \multicolumn{9}{|l|}{ Evening $(1700-2100)$} \\
\hline $\begin{array}{l}\text { Unexposed at } \mathrm{T} 1 \text { and } \mathrm{T} 2 \\
\text { Exposed only at } \mathrm{T} 1 \\
\text { Exposed only at } \mathrm{T} 2 \\
\text { Exposed at } \mathrm{T} 1 \text { and } \mathrm{T} 2\end{array}$ & $\begin{array}{r}37 \\
20 \\
4 \\
9\end{array}$ & $\begin{array}{l}114.9 \\
+2.3 \\
+3.4 \\
+8.5\end{array}$ & $\begin{array}{l}1.4 \\
2.2 \\
4.3 \\
3.0\end{array}$ & $\begin{array}{r}0.30 \\
0.43 \\
0.005\end{array}$ & $\begin{array}{r}64 \\
36 \\
6 \\
33\end{array}$ & $\begin{array}{r}177.7 \\
-0.4 \\
-0.6 \\
-0.3\end{array}$ & $\begin{array}{l}1.1 \\
1.7 \\
3.5 \\
1.7\end{array}$ & $\begin{array}{l}0.83 \\
0.86 \\
0.88\end{array}$ \\
\hline
\end{tabular}

a The total number of subjects in the evening differs slightly from the total at work because of missing data.

- $1 \mathrm{~mm} \mathrm{Hg}=0.133 \mathrm{kPa}$.

- The exposed categories were compared with the unexposed at both T1 and T2, using Student's t test; for a difference to be considered statistically

significant, the critical threshold was $\mathrm{P}=0.017$ (after the Bonferroni correction for an overall significant level of 0.05 )]

Adjusted for age, smoking, and use of oral contraceptives.

' Differences in blood pressure between the exposed categories (exposed only at T1, exposed only at T2, exposed at both T1 and T2) and the women unexposed at both $\mathrm{T} 1$ and $\mathrm{T} 2$. 


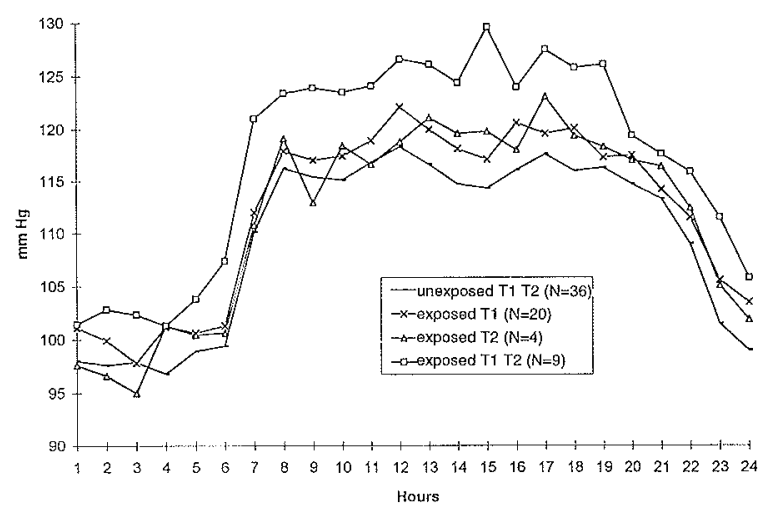

Figure 3. Hourly mean systolic blood pressure by cumulative job strain exposure among the women with a university degree, Quebec, 19911994. $(T 1=1991-1993, T 2=1993-1994,1 \mathrm{~mm} \mathrm{Hg} \approx 0.133 \mathrm{kPa})$

the women holding a university degree, those with high strain at both time 1 and time 2 had a significant elevation in systolic blood pressure of $8.2 \mathrm{~mm} \mathrm{Hg}(1.1 \mathrm{kPa})$ at work $(\mathrm{P}=0.004)$ when compared with the women unexposed at both time 1 and time 2 . This difference did not change from morning to afternoon (not shown) and was also similar in the evening. At night, there were no statistically significant differences between the exposure groups. Women exposed only at time 1 and women exposed only at time 2 had a slight but not significant elevation in blood pressure when compared with the women unexposed at both times. On the other hand, diastolic blood pressure was not significantly related to cumulative job strain (not shown). No significant difference according to cumulative job strain was observed among the women without a university degree. Figure 3 shows the hourly mean systolic blood pressure by cumulative job strain among the women with a university degree. Although present all day, the blood pressure difference between the women exposed to high strain at both times and the women unexposed at both times was more pronounced during the work and evening periods. Furthermore, over 24 hours, the systolic blood pressure elevation observed among the women exposed to high strain at both time 1 and time 2 was statistically significant $[7.7$ $\mathrm{mm} \mathrm{Hg}(1.0 \mathrm{kPa}) \mathrm{P}=0.001]$.

\section{Discussion}

The results of our study provide support for the effect of job-strain exposure on ambulatory blood pressure among women holding a university degree. Among these women, the $8.0 \mathrm{~mm} \mathrm{Hg}(1.1 \mathrm{kPa})$ and $6.4 \mathrm{~mm} \mathrm{Hg}(0.8 \mathrm{kPa})$ elevations in systolic and diastolic blood pressure seen respectively during work in the high-strain group are clinically significant. Indeed, it has been demonstrated in a meta-analysis of 9 prospective studies conducted among men and women that a persistent elevation of $5 \mathrm{~mm} \mathrm{Hg}$ $(0.7 \mathrm{kPa})$ in diastolic blood pressure increases the risk of a stroke by $34 \%$ and the risk of coronary heart diseases by $21 \%$ (38). The association between daytime ambulatory blood pressure and these end points was found to be stronger than that of office blood pressure $(39,40)$.

In our study, we used ambulatory measures of blood pressure taken over a 24-hour period for each subject. Such measurements are more valid than office measures. Ambulatory measures take into consideration the normal blood pressure level at work and outside work rather than the level measured in a clinic type of situation that may not be representative of real life. Ambulatory measures also control for blood pressure variability in relation to the observer or to the presence of medical personnel. Our ambulatory measures had twice the precision of a single measure (41). In addition, our measure of job strain, based on each worker's evaluation, avoids misclassification bias which could result from using a mean score for each occupation, which does not take into account the variance within an occupation. Even though the questionnaire seems to measure some "subjective" exposure to job strain, it was found that this individual measure was consistent with the evaluation of exposure conducted by experts (4). The method we used, which is associated with what workers think of their jobs, may be an important element in the effect on blood pressure.

Associations between job strain and blood pressure among the women holding a university degree were significant after adjustment for confounders. Missing data on hours spent laying down (sleeping period), reported in the diary, could have left some confounding in the association with the 24-hour blood pressure averages but not for other time periods since the other periods excluded the hours with missing data. We also evaluated whether certain observations had a large influence on the parameter estimates by using Cook's D measure of influence. Cook's D measures the change of the estimates that results from deleting each observation. No observation appeared to have a large influence. In our data, educational level, smoking, and oral contraceptive use were associated with blood pressure, as expected (42-45). Older women had a higher systolic blood pressure, which did not reach significance, possibly because of the small number of older women ( $\mathrm{N}=7$ ). The fact that body mass index and alcohol use were not associated with blood pressure could be explained by the exclusion of the women most exposed to these factors.

The limitations of our study relate mainly to its crosssectional design, which is subjected to differential selection and information bias (46). As Theorell et al (47) pointed out, it is unlikely that people with high blood pressure would choose high-strain jobs. It is, however, plausible that persons previously employed in high-strain jobs and experienced high blood pressure could move to low-strain jobs. Thus, if such a differential selection effect occurred, it would likely lead to an 
underestimation of the true association. As for differential information bias, it may have occurred if workers experiencing high blood pressure tended to perceive their work situation differently. Such a difference in perception may lead them to report their work situation as being more psychologically demanding. Such a tendency is also possible, although less likely, for low decision latitude. This bias would lead to an overestimation of the true association. However, the opposite effect is also possible if women with high blood pressure had a hampered ability to describe emotions and tended to underreport adverse life conditions (48). To assess this potential information bias, an additional analysis was conducted excluding women who had reported being told they had high blood pressure. This analysis yielded similar results. Another limitation of the present study relates to the participant selection criteria, which did not allow extrapolation of the results to all female white-collar workers in Quebec. In this regard, the percentage of women having a university degree was higher in our study population (34\%) than among all white-collar women in Quebec (18\%) (unpublished observations from the Quebec cardiovascular health survey, 1994). However, the overrepresentation of women with a higher education did not induce bias in our results since the analyses were stratified by education. Another limitation relates to the small sample size available for the study of the modifying effect of education observed in the data.

We evaluated whether the absence of association among the women without a university degree could be explained by a selection effect. The proportion of women excluded for each exclusion criteria at the time of the initial selection was similar according to the job-strain categories, but this was not the case for exclusions made in the 2 nd selection step. In fact, there were twice as many women excluded because they no longer worked in the same organization $(\mathrm{N}=76)$ among the women exposed to high strain $(23.8 \%)$ than among the women exposed to low strain $(12.4 \%)$. This difference was statistically significant $(\mathrm{P}=0.003$, Fisher's exact test). If job strain is truly related to higher blood pressure, these exclusions may have led to an underestimation of the true association. The possibility of differential selection according to educational level was then investigated. Among the women without a university degree, there were more than twice as many women excluded among the women with high strain because they no longer worked in the same organization $(25.2 \%)$ as among the women with low strain $(10.7 \%, \mathrm{P}=0.003$, Fisher's exact test). On the other hand, among the women holding a university degree, the proportion of exclusions for this criterion was more similar according to job-strain exposure (20.6 versus $15.2, P=0.50$, Fisher's exact test). These different proportions of women excluded according to educational level and job strain may have led to an underestimation of the true association among the women without a university degree and thus may explain why no association was found for these women. The percentages of women excluded for other reasons were similar according to educational level and job strain. We also evaluated whether the modifying effect of education could have been due to a more homogeneous distribution of the scores for the 2 job-strain scales among the women without a university degree in comparison with the women with a university degree. The distributions of the psychological demand scores and the decision latitude scores were found to be similar by educational level.

It is also possible that the observation of an association only among the women holding a university degree may have been due to a true modifying effect of education. Previous studies that found a positive association between job strain and blood pressure among women included subjects with mixed educational levels, but they did not evaluate the possible modifying effect of education $(8,12,14,15)$. Only 2 previous studies on job strain and blood pressure conducted among men evaluated the modifying effect of socioeconomic status on this association $(13,18)$. In the 1 st study, no statistically significant difference was found according to educational level (13). The 2nd study reported a stronger association among lower status workers (18), which is contrary to what we observed among women. However, women and men may differ in their blood pressure responses to job strain. Light et al (49) have recently reported that the effect of effort coping at work on blood pressure was higher among women with high job status than among other women, whereas no such modifying effect was observed among men. One possible explanation for the modifying effect of education could be the higher work expectations of women holding a university degree. When confronted with high psychological demands and low decisional latitude, the disappointment and frustration might be higher in women holding a university degree than in women who are not as educated and possibly have lower expectations. This higher frustration could induce higher strain and could result in a greater effect on blood pressure in these women. This hypothesis is partly supported by the study of Ross \& Reskin (50), in which the positive relationship between the control one has over one's work and job satisfaction was stronger among the highly educated than among the less educated. A second possible explanation for the modifying effect of education is that highly educated women, assuming that they have a higher level of job responsibilities than less educated women, have more conflict between work and family than lesseducated women. This stronger conflict could make highly educated women more vulnerable to other stressors, such as job strain. This hypothesis is partly supported by the work of Frankenhaeuser et al (51), who 
suggested that female middle managers, when compared with female clerical workers, experience the strongest conflict between work and home life.

Our findings among women with a university degree are consistent with the results of the studies of Van Egeren (8), Theorell et al (12), Blumenthal et al (14), and Laflamme et al (15). Three of these 4 studies used an ambulatory blood pressure measure $(8,12,14)$. On the other hand, 2 studies, which also used an ambulatory blood pressure measure, did not observe any association among women $(11,18)$. However, these 2 studies were conducted on very small samples of 64 (11) and 22 (18) women. In addition, the percentage of participants was either not provided (11) or very low (22\%) (18). Our findings for cumulative job strain over time (an average of 14 months) among women holding a university degree are consistent with a larger effect of blood pressure when duration of exposure is prolonged and with an effect that does not persist when exposure ceases. Schnall et al (20) reported similar findings. However, our results should be interpreted with caution given the limitations of the study in evaluating these temporal dimensions. These limitations are due particularly to the selection effect often present in cross-sectional studies, as discussed earlier. Thus, although we had some data on prior exposure, workers exposed for a prolonged period of time may have been underrepresented in our cross-sectional population. In addition, exposure prior to the 14 months preceding the study was not assessed. These features may underestimate the true effect of exposure duration.

In conclusion, the present findings provide support for the effect of job strain on ambulatory blood pressure measured at work, in the evening, and over a 24-hour period among female white-collar workers holding a university degree. The results provide no evidence of an effect among women without a university degree. Due to the highly selected sample, the results cannot be extrapolated to all female white-collar workers in Quebec. However, our results indicate that job strain may have an effect on blood pressure among female white-collar workers with a university degree. Further studies are needed to evaluate the possible modifying effect of education on the association between job strain and blood pressure. In addition, prospective studies are needed to evaluate the effect of prolonged exposure to job strain and the effect of exposure withdrawal on blood pressure. The issue of exposure withdrawal is particularly relevant for assessing the potential benefits of intervention studies aimed at reducing job strain in the workplace.

\section{Acknowledgments}

This work was supported by grants from the National Health Research and Development Program of Canada
(\#6605-4095-60B), the Medical Research Council of Canada (\#90090P-19499-CBA-35698), the Heart and Stroke Foundation of Quebec, and the Saint-Sacrement Hospital Foundation.

Chantal Brisson holds a national health research scholarship from Health Canada. The authors also wish to thank Marie Bégin and Carole Blanchette for their work with the data collection and surveys and Celine Valin for her clerical support.

\section{References}

1. Kristensen TS. Cardiovascular diseases and the work environment: a critical review of the epidemiologic literature on nonchemical factors. Scand J Work Environ Health 1989;15:165-79.

2. Schnall PL, Landsbergis PA, Baker D. Job strain and cardiovascular diseases. Ann Rev Public Health 1994;15:381-411.

3. Karasek RA Jr. Job demands, job decision latitude, and mental strain: implications for job redesign. Adm Sci Q 1979;24:285-308.

4. Karasek RA, Theorell T. Healthy work: stress, productivity and the reconstruction of working life. New York (NY): Basic Books, 1990.

5. Matthews KA, Cottington EM, Taibott E, Kuller LH, Siegel JM. Stressful work conditions and diastolic blood pressure among blue collar factory workers. Am J Epidemiol 1987;126:280-91.

6. Härenstam $\mathrm{AB}$, Theorell TPG. Work conditions and urinary excretion of catecholamines - a study of prison staff in Sweden. Scand J Work Environ Health 1988;14:257-64.

7. Netterstrøm B, Kristensen TS, Damsgaard MT, OIsen O, Sjol A. Job strain and cardiovascular risk factors: a cross sectional study of employed Danish men and women. Br J Ind Med 1991;48:684-9.

8. Van Egeren LF. The relationship between job strain and blood pressure at work, at home, and during sleep. Psychosom Med 1992;54:337-43.

9. Albright CL, Winkleby MA, Ragland DR, Fisher J, Syme L. Job strain and prevalence of hypertension in a biracial population of urban bus drivers. Am J Public Health 1992;82:9849.

10. Haratani T, Kawakami N, Araki S. Job stress and cardiovascular risk factors in a Japanese working population. Presented at the 9th International Symposium on Epidemiology in Occupational Health, Cincinnati, Ohio, 1992.

11. Light KC, Turner JR, Hinderliter AL. Job strain and ambulatory work blood pressure in healthy young men and women. Hypertension 1992;20:214-8.

12. Theorell T, Ahlbert-Hulten G, Jodko M, Sigala F, de la Torre $B$. Influence of job strain and emotion on blood pressure in female hospital personnel during workhours. Scand J Work Environ Health 1993;19:313-8.

13. Landsbergis PA, Schnall PL, Warren K, Pickering TG, Schwartz JE. Association between ambulatory blood pressure and alternative formulations of job strain. Scand $J$ Work Environ Health 1994;20:349-63.

14. Blumenthal JA, Towner Thyrum E, Siegel WC. Contribution of job strain, job status and marital status to laboratory and ambulatory blood pressure in patients with mild hypertension. 
J Psychosom Res 1995;39:133-44.

15. Laflamme N, Brisson C, Vézina M. Demande psychologique, latitude décisionnelle et tension artérielle chez des travailleurs québécois: mémoire de maîtrise. Quebec: Social and Preventive Medicine department, Laval University, 1992.

16. Steptoe A, Roy MP, Evans O, Snashall D. Cardiovascular stress reactivity and job strain as determinants of ambulatory blood pressure at work. J Hypertens 1995;13:201-10.

17. Greenlund K, Liu K, Knox S, McCreath H, Dyer A, Gardin J. Psychosocial work characteristics and cardiovascular disease risk factors in young adults: the Cardia Study. Soc Sci Med 1995;41:717-23.

18. Theorell T, Perski A, Åkerstedt T, Sigorla F, Ahlberg-Hultén $\mathrm{G}$, Svensson J, et al. Changes in job strain in relation to changes in physiological state: a longitudinal study. Scand J Work Environ Health 1988;14:189-96.

19. Chapman A, Mandryk JA, Frommer MS, Edye BV, Ferguson DA. Chronic perceived work stress and blood pressure among Australian government employees. Scand J Work Environ Health 1990:16:258-69.

20. Schnall PL, Schwartz JE, Landsbergis PA, Warren K, Pickering TG. The relationship between job strain and change in ambulatory blood pressure. Presented at the Annual Meeting of the American Public Health Association, San Francisco, California, 1993.

21. Pieper C, LaCroix AZ, Karasek RA. The relation of psychosocial dimensions of work with coronary heart disease risk factors: a meta-analysis of five United States data bases. Am J Epidemiol 1989;129:483-94.

22. Theorell T, de Faire U, Johnson J, Hall E, Perski A, Stewart W. Job strain and ambulatory blood pressure profiles. Scand J Work Environ Health 1991;17:380—5.

23. Theorell T, Knox S, Svesson J, Waller D. Blood pressure variations during a working day at age 28: effects of different types of work and blood pressure level at age 18. J Human Stress 1985:36-41.

24. Organisation de coopération et de dévelopement économique (OCDE). Eco-Santé, version 1.5. OCDE, 1993.

25. Haynes SG, Feinleib M. Women, work and coronary heart disease: prospective findings from the Framingham heart study. Am J Public Health 1980;70:133-41.

26. Hall EM. Gender, work control, and stress: a theoretical discussion and an empirical test. Int J Health Serv 1989;19:72545.

27. Rose GA. Chest pain questionnaire. Milkbank Mem Fund Q, 1965:32-9.

28. Karasek R. Job content questionnaire and user's guide. Los Angeles (CA): Department of industrial and systems engineering, University of Southern California, 1985.

29. Karasek RA, Schwartz J, Pieper C. Validation of a survey instrument for job-related cardiovascular illness. New York (NY): Columbia University, Department of Industrial Engineering and Operations Research, 1983.

30. Schnall PL, Schwartz JE, Landsbergis PA, Warren K, Pickering TG. Relation between job strain, alcohol, and ambulatory blood pressure. Hypertension 1992;19:488-94.

31. Laroque B, Brisson C, Blanchette C. Fidélité et validité de la version française des échelles de demande psychologique et de latitude décisionnelle du questionnaire de Karasek. Rev Épidémiol Santé Publique. In press.

32. Santé Québec. Et votre coeur, ça va? rapport de l'enquête québécoise sur la santé cardiovasculaire. Québec: Gouvernement du Québec, 1994.

33. Santé Québec. Et la santé, ça va? rapport de l'enquête Santé
Québec 1987. Québec: Gouvernement du Québec,1987.

34. Barefoot JC, Dodge KA, Peterson BL, Dahlstrom WG, Williams RB Jr. The Cook-Medley hostility scale: item content and ability to predict survival. Psychosom Med 1989;51:4657.

35. Haynes SG. Psychosocial scales and items used in the Framingham heart study. Am J Epidemiol 1978;107:382-3.

36. Taylor GJ, Bagy M, Ryan DP, Parker JDA. Validation of the alexithymia construct: a measurement-based approach. Can J Psychiatry 1990;35:290-7.

37. Kleinbaum DG, Kupper LL, Muller KE. Applied regression analysis and other multivariable methods. Boston (MA): PWS-KENT Publishing Company, 1988:30-2.

38. MacMahon S, Peto R, Cutler J, Collins R, Sorlie P, Neaton J, et al. Blood pressure, stroke, and coronary heart disease. Lancet 1990;335:765-74.

39. Perloff D, Sokolow M, Cowan R. The prognostic value of ambulatory blood pressures. JAMA 1983;249:2792-8.

40. Perloff D, Sokolow M, Cowan RM, Juster RP. Prognostic value of ambulatory blood pressure measurements: further analyses. J Hypertens 1989;7:S3—S10.

41. Radaelli A, Piepoli M, Adamopoulos S, Pipilis A, Clark SJ, Casadei B, et al. Effects of mild physical activity, atenonol and the combination on ambulatory blood pressure in hypertensive subjects. J Hypertens 1992;10:1279-82.

42. Shapiro AP, Rutan GH. Hypertension in women: differences and implications. In: Eaker ED, Packard B, Wenger NK, Clarkson TB, Tyroler HA, editors. Coronary heart disease in women. New York (NY): Haymark \& Doyma Inc, 1987:172-6.

43. Benowitz NL, Kuyt F, Jacob P, III. Influence of nicotine on cardiovascular and hormonal effects of cigarette smoking. Clin Pharmacol Ther 1984;36:74-81.

44. Dyer AR, Stamler J, Shekelle R, Schoenberger J. The relationship of education to blood pressure. Circulation 1976;54:987-92.

45. The Joint National Committee on Detection Evaluation and Treatment of High Blood Pressure. The fifth report of the Joint National Committee on Detection, Evaluation, and Treatment of High Blood Pressure (JNC V). Arch Intern Med 1993;153:154-83.

46. Checkoway H, Pearce NE, Crawford-Brown DJ. Research methods in occupational epidemiology. New York (NY): Oxford University Press, 1989:332

47. Theorell T, Alfredsson L, Knox S, Perski A, Svensson J, Waller D. On the interplay between socioeconomic factors, personality and work environment in the pathogenesis of cardiovascular disease. Scand J Work Environ Health 1984:10:373-80.

48. Theorell T. Family history of hypertension - an individual trait interacting with spontaneously occurring job stressors. Scand J Work Environ Health 1990;16:74 -9.

49. Light KC, Brownley KA, Turner JR, Hinderliter AL, Girdler SS, Sherwood A, et al. Job status and high-effort coping influence work blood pressure in women and blacks. Hypertension 1995;25:554-9.

50. Ross CE, Reskin BF. Education, control at work, and job satisfaction. Soc Sci Res 1992;21:134-48.

51. Frankenhaeuser M, Lundberg U, Fredrikson M, Melin B, Tuomisto M, Myrsten AL. Stress on and off the job as related to sex and occupational status in white-collar workers. J Organ Behav 1989:10:321-46.

Received for publication: 2 September 1997 